\title{
Large-Scale Atmospheric Circulation Favoring Deep- and Intermediate-Water Formation in the Mediterranean Sea
}

\author{
VASSILIS P. PAPAdopoulos, * Simon A. Josey, ${ }^{+}$Aristides BARTZOKAS, \\ SAMUEL SOMOT, ${ }^{@}$ SIMON RUIZ, ${ }^{\&}$ AND PARASKEVI DRAKOPOULOU** \\ * Hellenic Center for Marine Research, Patras, Greece \\ ${ }^{+}$National Oceanography Centre, Southampton, United Kingdom \\ \# Department of Physics, University of Ioannina, Ioannina, Greece \\ @ Météo-France (CNRM-GAME), Centre National de Recherches Météorologiques, Toulouse, France \\ \& IMEDEA (CSIC-UIB), Mallorca, Spain \\ ** Hellenic Center for Marine Research, Anavissos, Greece
}

(Manuscript received 9 November 2011, in final form 7 March 2012)

\begin{abstract}
Atmospheric circulation patterns that are conducive to extreme ocean heat loss are investigated at four sites of special interest in the Mediterranean Sea. The Gulf of Lions, the South Adriatic Sea, the Cretan Sea, and the Levantine Sea are areas where anomalously high winter heat loss may lead to deep- or intermediate-water formation. At each of the above sites, the atmospheric circulation during such events is derived by averaging the sea level pressure (SLP) fields during the lower decile of the wintertime series of the net heat exchange. A relatively simple SLP pattern dominated by an anticyclone over northwestern Europe with a weaker cyclone to the southeast is found to be associated with strong heat loss in the selected sites with minor variations in pattern structure depending on the site. The SLP composite pattern reflects the combined effect of different atmospheric modes of variability and the authors consider the impacts on heat loss of a number of these modes (North Atlantic Oscillation, east Atlantic pattern, east Atlantic-west Russia pattern, and Scandinavian pattern), together with the North Sea-Caspian pattern and the Mediterranean index. The extremes in heat loss are strongly connected with the intensity and the positions of the poles of these patterns that modulate, through the necessary SLP gradient and associated northerlies, the transfer of cold and dry air over the areas of dense-water formation. Analysis of air-sea temperature difference, specific humidity, and evaporation anomalies indicates that the extremes of the net heat fluxes are primarily due to the latent and sensible heat flux components.
\end{abstract}

\section{Introduction}

Air-sea heat exchange is a key factor influencing the dynamical behavior of both the ocean and atmosphere. The interaction between the ocean and the atmosphere plays a crucial role for the climate system on a global scale through its influence on vital processes, including the oceanic thermohaline circulation and large-scale atmospheric circulation. Furthermore, the impacts of underway global warming make the better understanding of the air-sea heat exchange more critical. For example, increase in SST and strong positive buoyancy over traditional sites of intermediate- or deep-water

Corresponding author address: Vassilis P. Papadopoulos, Hellenic Centre for Marine Research, Institute of Oceanography, $46.7 \mathrm{Km}$ Athinon-Souniou Ave., Anavissos, Attica 19013, Greece.

E-mail: vassilis@hcmr.gr formation may prevent or reduce the deep-water oxygenation. The future adjustment and evolution of the global ecosystem is directly linked to the response and feedback of the air-sea heat flux to climate change.

The Mediterranean is a marginal sea located across a dynamic border that separates two different climatic areas: Europe and North Africa. One of the most important oceanographic characteristics of the Mediterranean Sea is the deep-water convection occurring at several locations. The dense water sinking is part of the thermohaline conveyor belt and is driven by the atmospheric conditions prevailing during winter along with the hydrographic characteristics of the water column (Theocharis et al. 1999). The water convection is a crucial process for the marine ecosystem, inasmuch as it oxygenates the deeper seawater layers and prevents anoxic conditions. 


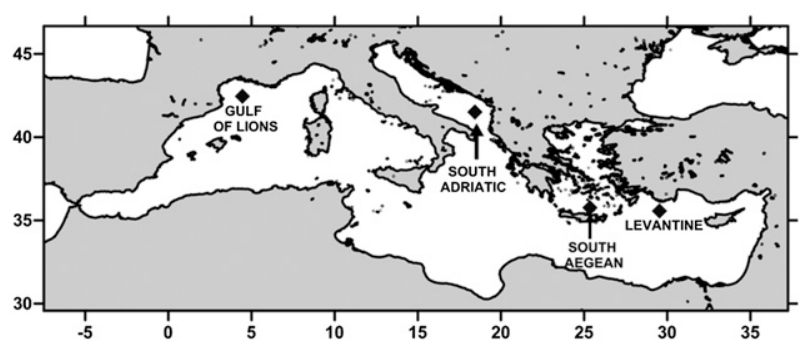

FIG. 1. The major locations of deep- and intermediate-water formation in the Mediterranean Sea.

There are several important locations of deep and intermediate water in the Mediterranean Sea (Fig. 1). In the western subbasin, the Gulf of Lions has been recognized as the major area of deep convection and the main source of the Western Mediterranean Deep Water (WMDW; MEDOC Group 1970; Marshall and Schott 1999). In the eastern subbasin, the Adriatic Sea is the long-term source for the Eastern Mediterranean Deep Water (EMDW; Artegiani et al. 1997). However, in the mid-1990s, after a period of successive severe winters in the Aegean, and milder ones in the Adriatic, the Aegean Sea temporarily became the major source for the EMDW (Roether et al. 1996, 2007). In addition, the Levantine Sea is a place of intermediate-water formation [Levantine Intermediate Water (LIW)] usually during late winter (Özsoy et al. 1993). The LIW is found almost everywhere in the Mediterranean Sea and thanks to its high salinity, contributes to the deep-water formation at all the aforementioned locations (Wu and Haines 1996; Samuel et al. 1999; Wu et al. 2000; Schröeder et al. 2010; Herrmann et al. 2010).

The net air-sea heat flux $\left(Q_{\text {net }}\right)$ is the sum of four components, the shortwave radiation (SW), the longwave radiation $(\mathrm{LW})$, the latent heat $(\mathrm{LH})$, and the sensible heat $(\mathrm{SH})$ :

$$
Q_{\text {net }}=\mathrm{SW}+\mathrm{LW}+\mathrm{LH}+\mathrm{SH} .
$$

The shortwave and longwave radiation are the radiative components and the latent and sensible heat are the turbulent terms. On various time scales, the turbulent heat flux components are strongly influenced by local weather conditions, as they depend on near-surface temperature and humidity gradients as well as wind speed that, in turn, depend on the general atmospheric circulation (Cayan 1992; Alexander and Scott 1997; Bond and Cronin 2008; Konda et al. 2010). Severe surface cooling events are a fundamental precondition for triggering deep convection in the Mediterranean Sea (Herrmann and Somot 2008; Beuvier et al. 2010; Herrmann et al. 2010) and are closely related to the atmospheric forcing.
The impact of the large-scale atmospheric circulation on the surface heat exchanges over the Mediterranean basin has been recognized by many researchers. Josey (2003) attributed periods of severe cooling in the eastern Mediterranean to distinct SLP patterns that enable the transfer of cold and dry air masses from the continental Europe over the Aegean Sea. Gündüz and Özsoy (2005) described the influence of the North Sea-Caspian Pattern (NCP) on several variables over the Mediterranean region. They related periods of abnormal cooling over the eastern basin with atmospheric patterns similar to those reported by Josey (2003). Recently, Josey et al. (2011) examined the impacts of atmospheric variability on the surface heat exchange and linked anomalous heat loss with specific atmospheric modes. They considered four independent modes - the North Atlantic Oscillation (NAO), east Atlantic pattern (EA), Scandinavian pattern (SCAN), and east Atlantic-west Russia pattern (EAWR) - and found that two of them (EA and EAWR) had strong impacts. In particular, the EA resulted in heat flux anomalies of similar sign across the basin, while the EAWR produced a dipole response with anomalies of approximately equal and opposite sign in the eastern and western subbasins. Importantly, the four modes they considered were all independent as they were generated by an orthogonal analysis carried out at the National Oceanic and Atmospheric Administration/Climate Prediction Center (NOAA/CPC). Finally, Papadopoulos et al. (2012a) examined the net heat flux variability over the Aegean Sea using a broader set of atmospheric modes and obtained results consistent with Josey et al. (2011) as the events of severe cooling could be attributed to distinctive SLP patterns with the EA and EAWR dominant. The above studies point out that there is a remarkable coupling between events of extreme surface cooling and the large-scale SLP configuration in the Mediterranean Sea. In general, the patterns favoring abnormal heat loss are associated with the transfer of cold and dry air masses over the Mediterranean basin.

The study at hand investigates large-scale SLP patterns that have the potential to trigger deep convection processes over the four areas at which dense water formation frequently occurs (Fig. 1). This work is an extension of Papadopoulos et al. (2012a), which referred only to the Aegean Sea. We consider the SLP fields that favor the surface buoyancy loss induced by extreme atmospheric cooling. In a complementary approach to recent work, we focus on the SLP field that results from compositing on extreme heat loss as opposed to the specific response to climate mode indices, although we do supplement our analysis with correlation measures for several of these modes. Undoubtedly, the climatic indices are very powerful tools in examining the climatology of the surface heat exchanges over the Mediterranean Sea (Josey et al. 2011). However, 
when considering specific deep-water formation sites, the detailed SLP features that may provoke severe surface cooling may not be isolated by the mode index approach. This paper contributes to the identification of such features. The text is organized as follows. Section 2 comprises the data used in the study and section 3 describes the methodological approach. The results are presented in section 4, while section 5 summarizes the main outputs of the article.

\section{The datasets}

The study is based on the low-frequency variability of two key parameters. First, the net air-sea heat flux at the four areas of interest in the Mediterranean Sea and second, the SLP. For the net heat flux, we use monthly mean values from two downscaled reanalysis datasets, the Spanish Hindcast of Dynamic Process of the Ocean and Coastal Areas of Europe (HIPOCAS) that spans the 44-yr period, 1958-2001 (Sotillo et al. 2005; Ratsimandresy et al. 2008), and the French ARPEGE climate model driven by the European Centre for Medium-Range Weather Forecasts (ECMWF) Re-Analysis (ERA) fields (ARPERA) that spans the 50-yr period, 1958-2007 (Herrmann and Somot 2008; Herrmann et al. 2010). Both of these datasets have a fine resolution of $0.5^{\circ}$ in both latitude and longitude. Regarding the SLP and the surface wind we use monthly mean values retrieved from the National Centers for Environmental Prediction-National Center for Atmospheric Research (NCEP-NCAR) reanalysis dataset (Kalnay et al. $1996)$ in a $2.5^{\circ}$ by $2.5^{\circ}$ resolution. The same reanalysis archive is used for the calculation of the NCP according to Gündüz and Özsoy (2005) and the Mediterranean index (MI) according to Papadopoulos et al. (2012b). The climatic indices NAO, EA, EAWR, and SCAN are retrieved from the NOAA/CPC and represent the primary modes of atmospheric variability of the broad Eurasia region (Barnston and Livezey 1987). Moreover, we use monthly values from the archive of the objectively analyzed air-sea fluxes (OAFlux) for the global oceans project at Woods Hole Oceanographic Institution (WHOI; Yu and Weller 2007) for the air temperature, sea surface temperature (SST), specific humidity, and evaporation over the Mediterranean Sea with a grid resolution of $1^{\circ}$ in both latitude and longitude.

\section{Methodology}

The study focuses on extreme values of net air-sea heat flux variability over the four Mediterranean areas, where convection occurs during winter. To make the results more robust, we use the net air-sea heat flux from two separate databases. We compose time series for the cold period of the year, comprising monthly values from November to March averaging the net heat flux over an area that encompasses eight grid points at each studied location. For each one of the four areas, we use four successive in longitude and two in latitude grid points (a rectangle $2^{\circ}$ by $1^{\circ}$ ). Next, we segregate out the highest and lowest $10 \%$ of all wintertime monthly heat flux values that is the two outermost deciles of the whole wintertime series (note heat flux is defined here to be negative for ocean heat loss, so the term lowest refers to the strongest heat loss while the highest means the weakest heat loss). We also include the study of the highest net heat flux values for climatic reasons and for giving emphasis to the contrast with the lowest decile. Since the ARPERA dataset includes $50 \mathrm{yr}$ of monthly mean values, each dataset consists of 250 values [November-March (NDJFM) 5 months $\times 50 \mathrm{yr}$ ]. Consequently, each decile corresponds to 25 monthly mean values. For these 25 values we average the corresponding SLP and SLP anomalies (SLPA) to produce the representative composites for each case at each location. Special attention is given to the contribution of each heat flux component to the total energy anomaly of each extreme case. Especially for the lowest decile that favors conditions of extreme cooling, we present the concurrent composites of the wind field and the anomalies of the air-sea temperature difference $\left(T_{\text {air }}-T_{\text {sea }}\right)$, the specific humidity, and the evaporation. The component contributions and the additional composites are presented in an effort to elucidate the physical mechanisms controlling the excessive heat loss. Furthermore, we apply a linear correlation between the extremes and the selected climatic indices. For the correlation analysis, the top and bottom deciles (i.e., the 25 highest and 25 lowest heat wintertime heat flux months) are combined into a single time series that is correlated to the indices time series. The indices implemented in this study are the NAO (Hurrell 1995), the EA (Wallace and Gutzler 1981), the EAWR (Krichak et al. 2002), and SCAN (Rogers 1990). The above indices represent the leading four modes of the atmospheric variability in the North Atlantic/Eurasia region (Rogers 1990; Krichak et al. 2002) according to the NOAA/CPC analysis. In addition, we include two more indices of high interest for the Mediterranean region: the NCP (Kutiel and Benaroch 2002) and the MI (introduced by Papadopoulos et al. 2012b). The MI represents the anomaly of sea level pressure (SLP) difference between southern France $\left(45^{\circ} \mathrm{N}\right.$, $\left.5^{\circ} \mathrm{E}\right)$ and the Levantine Sea $\left(35^{\circ} \mathrm{N}, 30^{\circ} \mathrm{E}\right)$ and was found to have a strong but area-dependent impact on the turbulent air-sea heat fluxes over the Mediterranean Sea.

\section{Results and discussion}

\section{a. SLP patterns}

Figure 2 shows the SLP composites that correspond to the lowermost decile of the net heat exchange $\left(Q_{\text {net }}\right)$ 

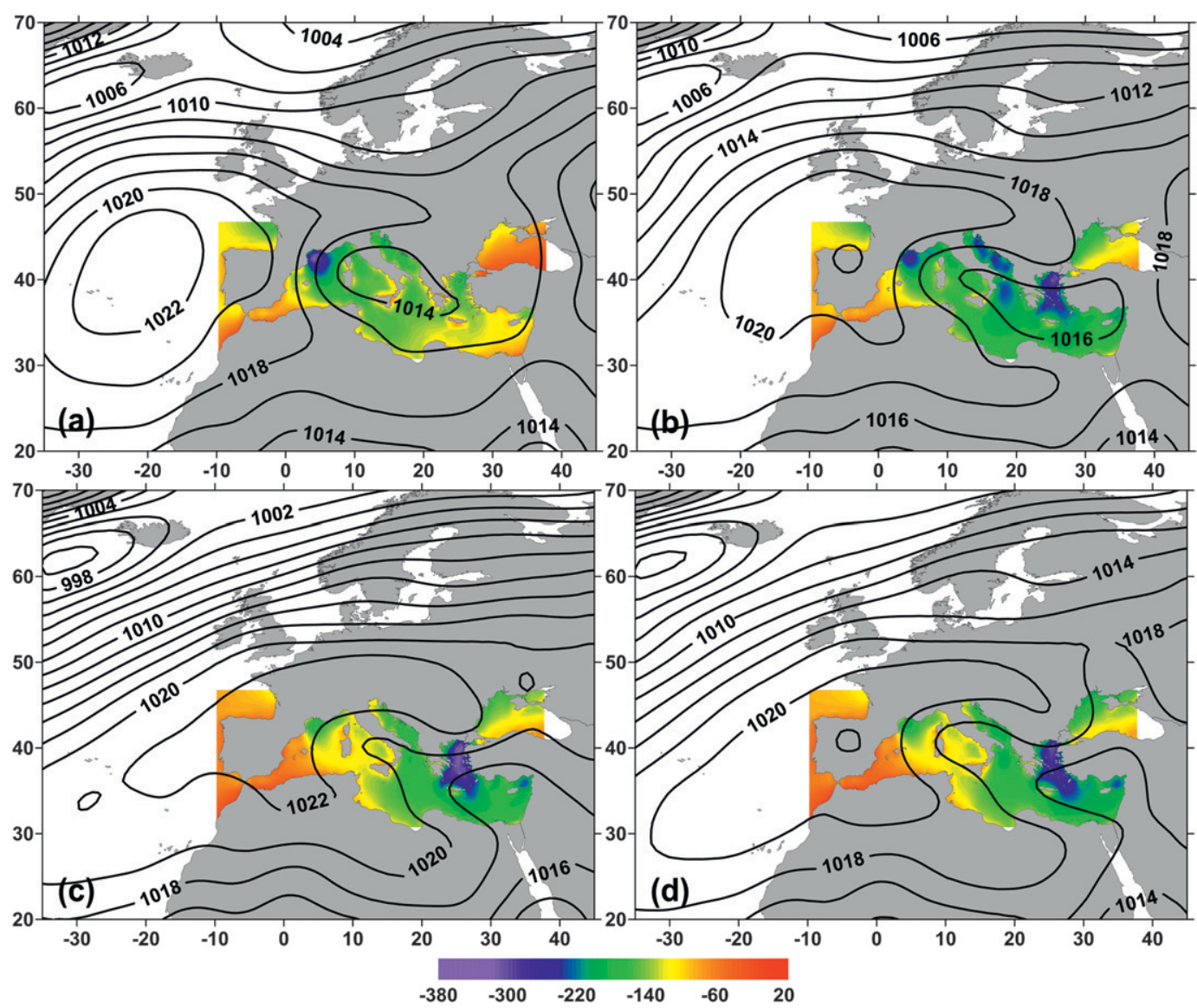

FIG. 2. Composites of SLP field (hPa) and mean net heat flux $\left(\mathrm{W} \mathrm{m}^{-2}\right)$ corresponding to the lowermost decile of $Q_{\text {net }}$ values occurring in winter (NDJFM) during the 50-yr period, 1958-2007, for each of the studied sites: (a) Gulf of Lions, (b) Adriatic Sea, (c) Cretan Sea, and (d) Levantine Sea.

values occurring in winter during the 50 -yr period, 1958 2007 , for each of the studied sites. It has to be clarified again that the lowest $Q_{\text {net }}$ values are associated with the strongest atmospheric forcing. It is seen that, in general, the Mediterranean Sea appears as a relatively low pressure "lake" due to the warm water influence on the atmosphere compared to the surrounding cold lands. In central Europe and North Africa high pressures prevail due to subsidence of air masses over the cold land. The subtropical anticyclone of the Atlantic (Azores high) and the low pressure system of Iceland, pressure systems of dynamic origin, are also seen in all maps. For the Gulf of Lions (Fig. 2a), the minima of $Q_{\text {net }}$ occur under the combination of the Azores high and a central Mediterranean low. This SLP configuration presents a strong pressure gradient over the Gulf of Lions area favoring there the cold, dry mistral wind flow (Estournel et al. 2003). Consequently, the cold and dry strong wind enhances the heat loss by the sea resulting in surface cooling. The eastward shift of the anticyclone and the extension of the low pressures to the southeast favor the heat flux minima over the Adriatic Sea (Fig. 2b). This SLP structure creates a northeast wind conducive to the heat flux minima. Similarly to the Gulf of Lions, the SLP arrangement favors the transfer of continental dry, cold air from higher latitudes. Likewise, the combination of the high pressures over Europe and the low pressures over eastern Mediterranean is responsible for the extreme heat loss over the Cretan (South Aegean) and Levantine Seas (Figs. 2c,d). The composites show a clear difference of the SLP configuration between the western and the eastern Mediterranean. The common characteristic in all cases is the existence of the SLP gradient that enhances the negative meridional wind component transferring dry and cold air masses over the studied areas.

The differences between the SLP patterns associated with each site are seen more clearly in the SLPA fields under which the lowest $Q_{\text {net }}$ values occur (Fig. 3). The heat flux minima over the Gulf of Lions are associated with strong positive SLPA higher than $+9 \mathrm{hPa}$ over the 

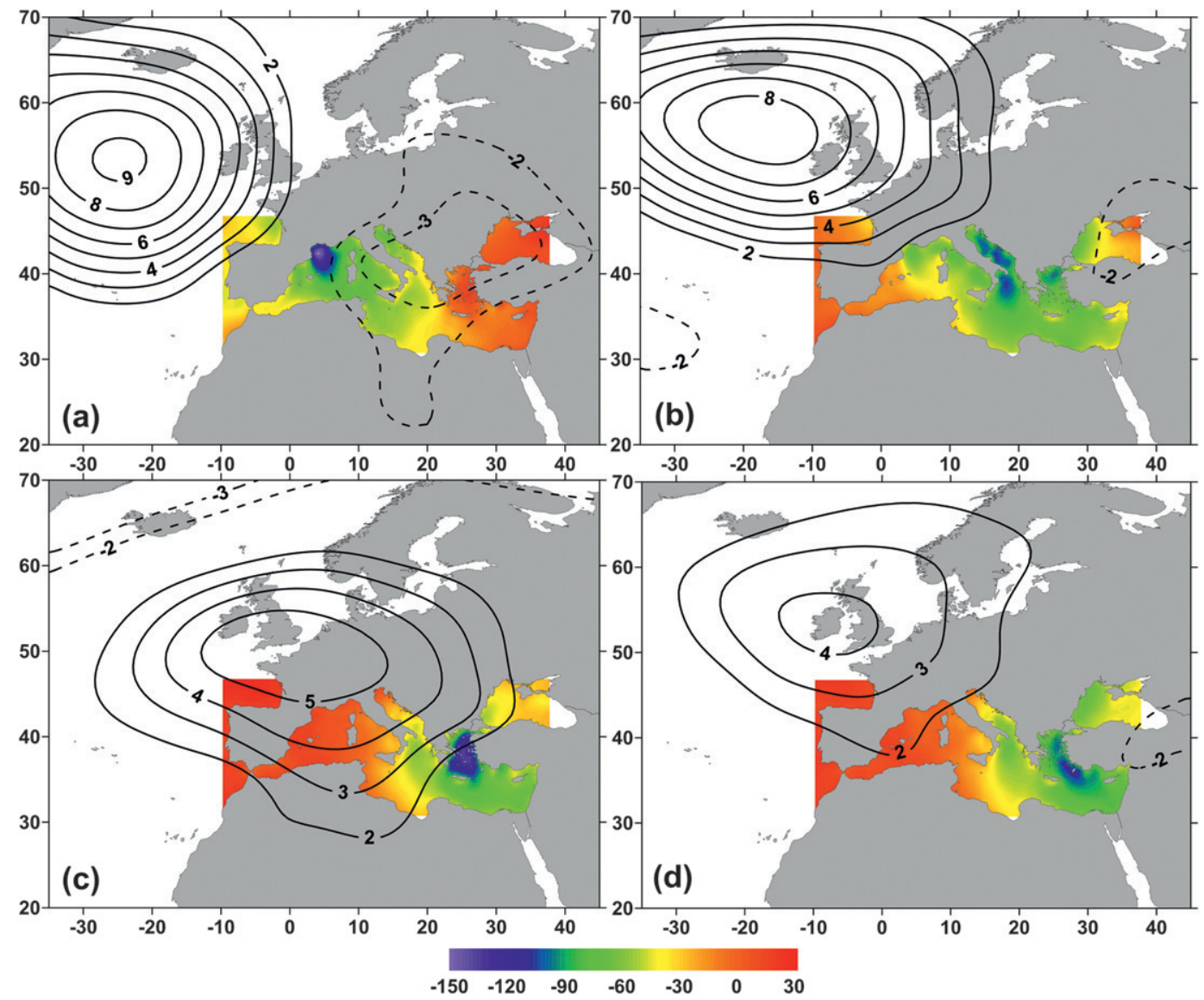

FIG. 3. As in Fig. 2, but for the composites of SLP anomalies and the mean net heat flux anomaly.

northeastern Atlantic and a secondary cyclonic feature characterized by negative SLPA lower than $-3 \mathrm{hPa}$ over the Balkan Peninsula (Fig. 3a). A similar pattern of SLPA with values higher than $+8 \mathrm{hPa}$, slightly shifted eastward, appears for the Adriatic Sea $Q_{\text {net }}$ minima although the secondary cyclonic feature is now much weaker (Fig. 3b). The SLPA composites for the Cretan and Levantine are also characterized by positive SLPAs around +5 hPA over northwestern Europe (Figs. 3c,d), although the strength of the pattern is now a little weaker particularly for the Levantine. The opposite occurs in the SLPA composites for the upper decile of the $Q_{\text {net }}$ values. SLPA show a configuration that is characterized by the reverse of polarity of the patterns associated with the lower decile. Moreover, the general circulation favors the prevailing of wet and warm southerlies over the studied areas especially for the Gulf of Lions and Cretan Seas (Figs. 4b,c).

\section{b. Wind, temperature, and humidity anomalies}

Figure 5 shows the significant role of the wind field over the Mediterranean during the extreme cooling events. Extreme surface heat loss is linked to northnorthwest flow over the Gulf of Lions (Fig. 5a), northeast winds over the Adriatic Sea (Fig. 5b), north winds over Cretan Sea (Fig. 5c), and northwest winds over the Levantine Sea (Fig. 5d). The wind speed anomaly ranges from $1 \mathrm{~m} \mathrm{~s}^{-1}$ for the Levantine Sea to $2 \mathrm{~m} \mathrm{~s}^{-1}$ for the Gulf of Lions. In addition to the direct effect on the turbulent heat loss of the wind speed anomaly, a further factor is the anomalous wind direction which results in the advection of dry and cold air masses from much higher latitudes. This is evident over all the studied sites and especially for the Levantine Sea where a relatively small wind speed anomaly is linked with anomalous airflow from Scandinavia through eastern Europe (Fig. 5d). However, the low anomalies might also be attributed to the low resolution of the NCEP-NCAR $\left(2.5^{\circ}\right)$. Several parameters associated with the wind regime intensify the heat loss by the sea. Thus, the transfer of cold air over the studied areas during extreme heat loss causes negative $T_{\text {air }}-T_{\text {sea }}$ anomalies. This is evident for the $T_{\text {air }}-T_{\text {sea }}$ anomalies accompanying the lowest $Q_{\text {net }}$ values shown in Fig. 6. High negative anomalies reveal 

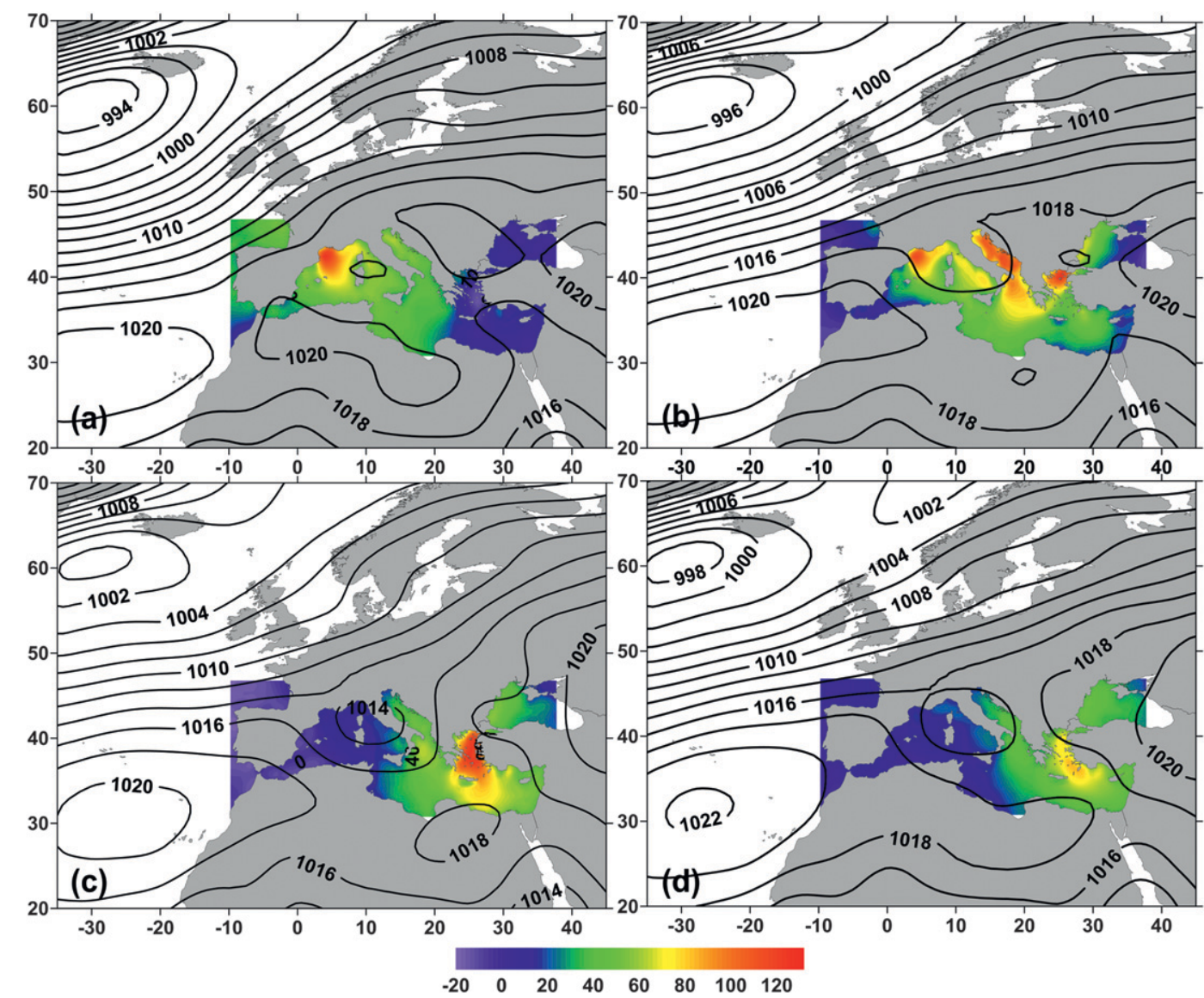

FIG. 4. As in Fig. 2, but for the composites of SLP anomalies and the mean net heat flux anomaly for the uppermost decile.

the transfer of extreme cold air masses during the cooling events over the sites of potential deep convection. As noted in the analysis of the SLP fields, extreme events of heat loss in the western and the eastern Mediterranean basins display dissimilar spatial distribution of the anomaly values. In particular, the patterns corresponding to the Cretan and Levantine Seas (Figs. $6 c, d)$ exhibit almost the same spatial variability indicating simultaneous cooling of the two areas.

Similar results also hold for the anomalies of the specific humidity illustrated in Fig. 7. The dry, continental northerlies over the studied areas are expected to reduce the specific humidity enhancing the evaporation and the heat loss through the latent heat. Indeed, in all cases, negative specific humidity anomalies are associated with the minima of $Q_{\text {net }}$. The spatial distributions of the anomalies are similar again for the Cretan and Levantine Seas (Figs. 7c,d). The mixture of strong wind and dry air is expected to cause enhanced evaporation over the studied areas during the cooling events. The spatial distribution of the evaporation anomalies during these events confirms the increase of evaporation (Fig. 8). The anomaly patterns are inverse between western and eastern Mediterranean regions. Strong positive evaporation anomalies over the western basin are associated with normal or slightly negative anomaly values over the eastern basin and vice versa. The evaporation regimes associated with the $Q_{\text {net }}$ minima over the Cretan and Levantine Seas are observed to be spatially similar (Figs. $8 \mathrm{c}, \mathrm{d})$ and this is known to be a region where wind and evaporation maxima are closely associated (Romanou et al. 2010).

\section{c. Component contributions and mode impacts}

An additional interesting characteristic is the contribution of each component to the modulation of the extremes of net heat flux at each area. Figure 9 presents the contribution of each component to the total energy anomaly for each extreme case (top or bottom). Clearly, the two turbulent components, the latent and sensible heat, regulate the minima and the maxima of the net heat flux in all cases, with the latent being dominant. The shortwave radiation exhibits the lowest contribution ranging from $0 \%-5 \%$ of the total energy anomaly. The 


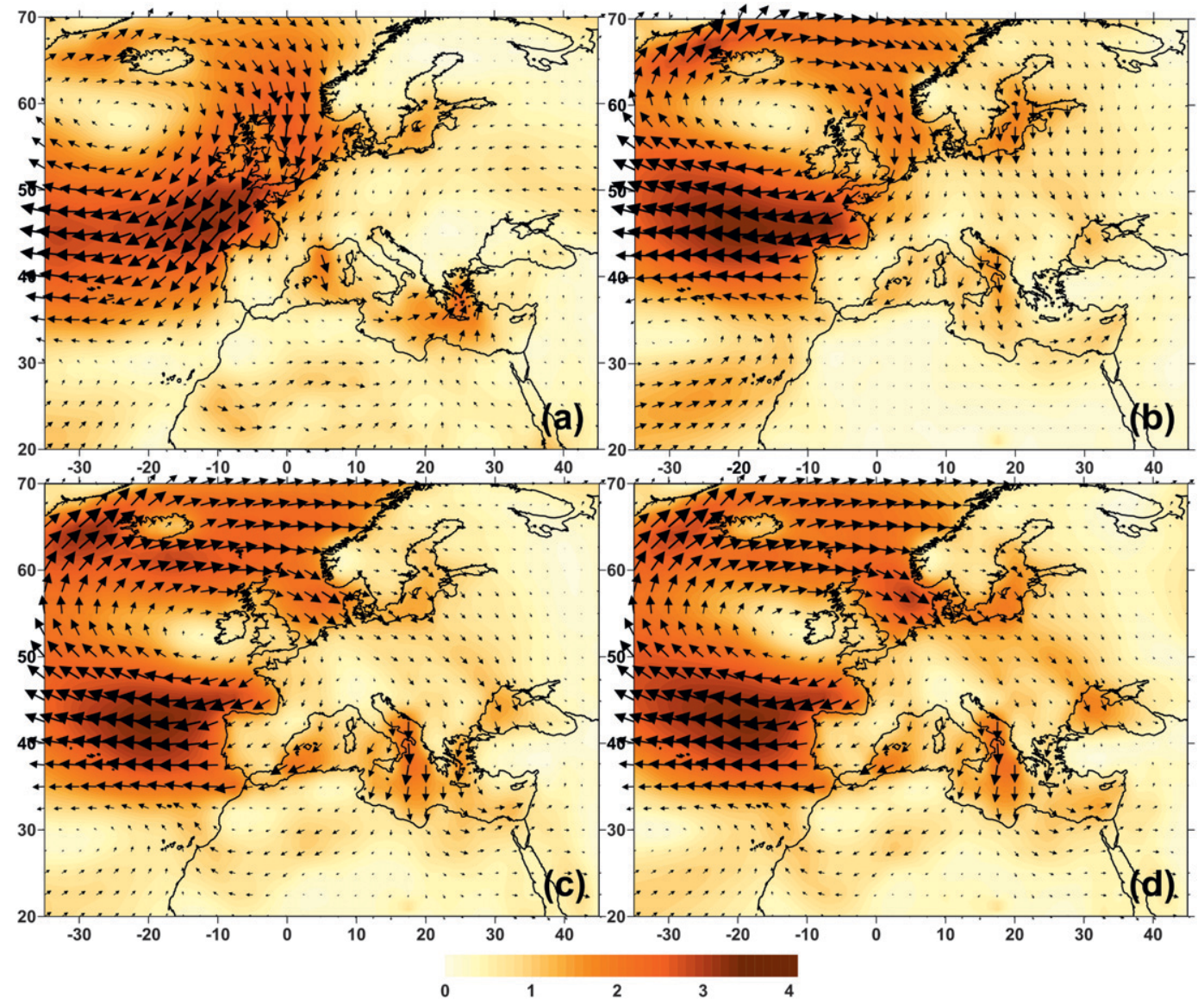

FIG. 5. As in Fig. 2, but for the wind anomalies field $\left(\mathrm{m} \mathrm{s}^{-1}\right)$.

longwave radiation has also a minor contribution between $6 \%-16 \%$. In contrast, the turbulent terms dominate with the latent heat contribution ranging from $54 \%-71 \%$ and sensible heat from $18 \%-30 \%$. This is strong evidence for the wind influence on the air-sea heat flux regime over the whole Mediterranean basin. Indeed, the turbulent components are strongly affected by the wind speed and the wind direction. For example, strong winds intensify the amount of the turbulent fluxes and the direction regulates the specific humidity. Winds blowing from the land transfer drier air masses than winds coming from the sea and increase the heat loss by means of latent heat. On the other hand, the radiative terms show a limited contribution to the formation of extremes mainly by the anomalies of the longwave radiation, which depends also on the $T_{\text {air }}-T_{\text {sea }}$ and the specific humidity regimes. Cold air over warm sea and low specific humidity values due to continental wind enhance the heat loss through the longwave radiation.

The analysis of the SLP and SLPA composites reveals the atmospheric circulation favoring deep convection events. The SLPA patterns, especially for the Gulf of
Lions and the Adriatic Sea, imply that the EA pattern may trigger the deep convection events. To elucidate the impact of the atmospheric modes on the extremes of surface heat exchange, we employ a linear correlation between six climatic indices and the extreme values, including minima and maxima of the heat fluxes separately at each area. As noted in the methodology section, the six climatic indices are NAO, EA, EAWR, SCAN, NCP, and MI. The MI is used for examining the SLP effects on the basis of an intrabasin index since MI represents anomalies of the SLP difference between south France and the Levantine Sea (Papadopoulos et al. 2012b). It should be clarified that only the first four of these indices are independent; the NCP and MI may reflect some combination of the independent ones.

Table 1 summarizes the correlation coefficients between the indices and the extreme anomalies of $Q_{\text {net }}$ (both upper and lower deciles). Given the 50 pairs under consideration for each region, the statistically significant coefficients are greater than 0.27 or 0.35 (absolute values) for confidence levels $95 \%$ or $99 \%$, respectively. Considering the independent modes first, the results 

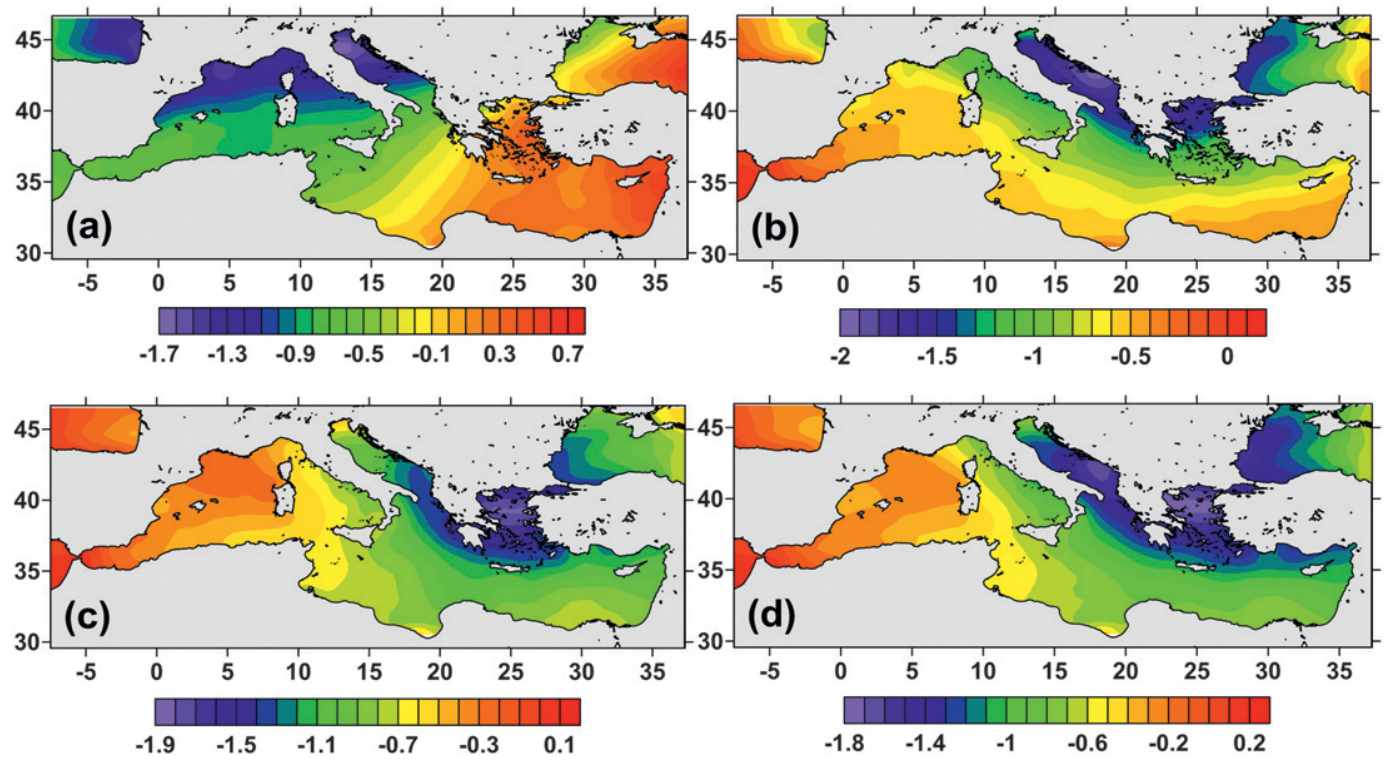

FIG. 6. As in Fig. 2, but for the anomalies of the difference between air and sea temperatures.

reveal significant correlations for the EA and EAWR that are consistent with the complementary analysis at the subbasin scale of Josey et al. (2011). In particular, the EA exhibits a rather spatially uniform influence, with positive correlations greater than 0.5 at all sites and highest values $(r=0.80)$ in the Gulf of Lions and Adriatic Sea. In contrast, the EAWR has an opposite influence between sites located in the two subbasins, in agreement with the conclusions of Josey et al. (2011) that this mode has an approximately equal and opposite effect on the heat budget of the eastern and western Mediterranean. The correlation statistics for the $\mathrm{NCP}$ are close to those obtained for the EAWR pattern suggesting that it cannot be considered to be an independent mode. A correlation analysis of the indices for each of these modes reveals $r=$ 0.64 . The NAO exhibits a weak correlation with the heat flux extremes and the SCAN pattern shows no significant correlation with extreme events.

The MI is significantly correlated with heat flux extrema at the three eastern sites, but does not capture the processes associated with strong heat loss in the Gulf of Lions. The strongest correlation $(r=-0.85)$ is found
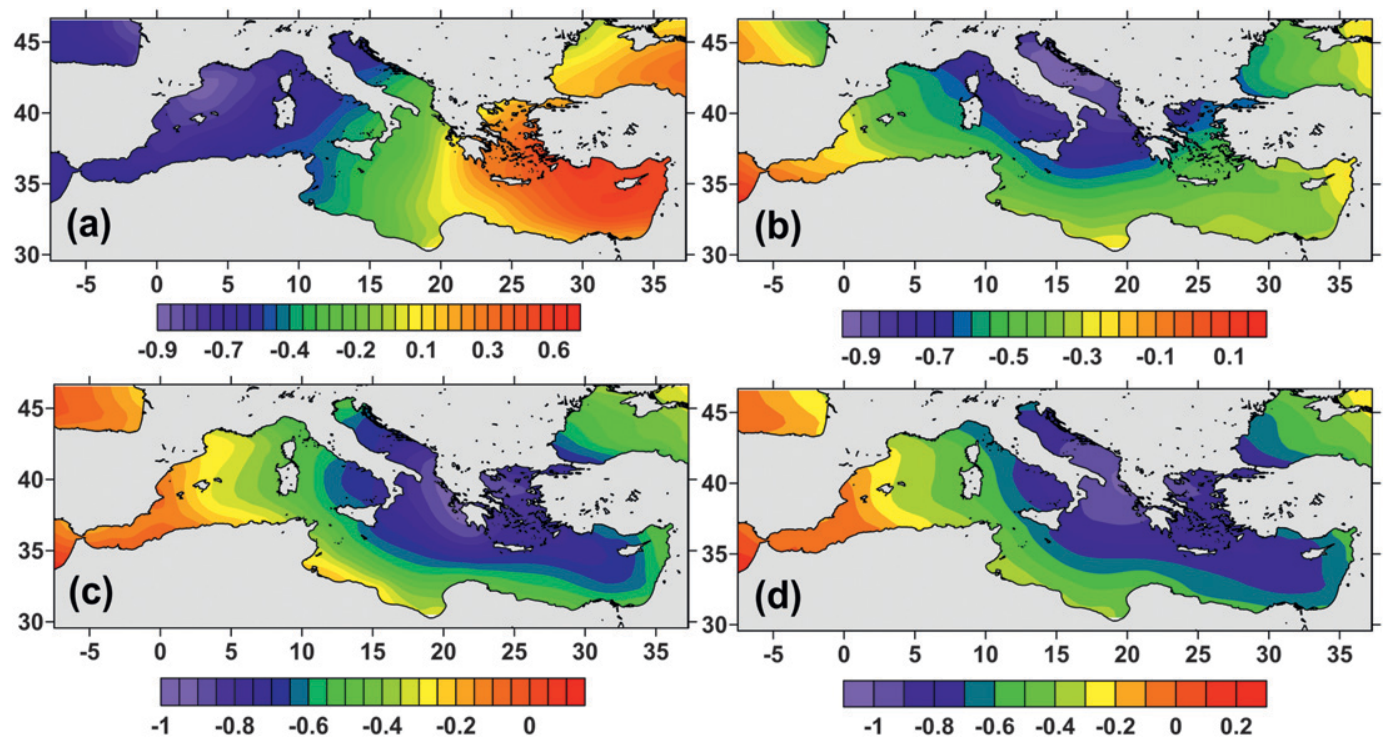

FIG. 7. As in Fig. 2, but for the anomalies of the specific humidity $\left(\mathrm{g} \mathrm{kg}^{-1}\right)$. 

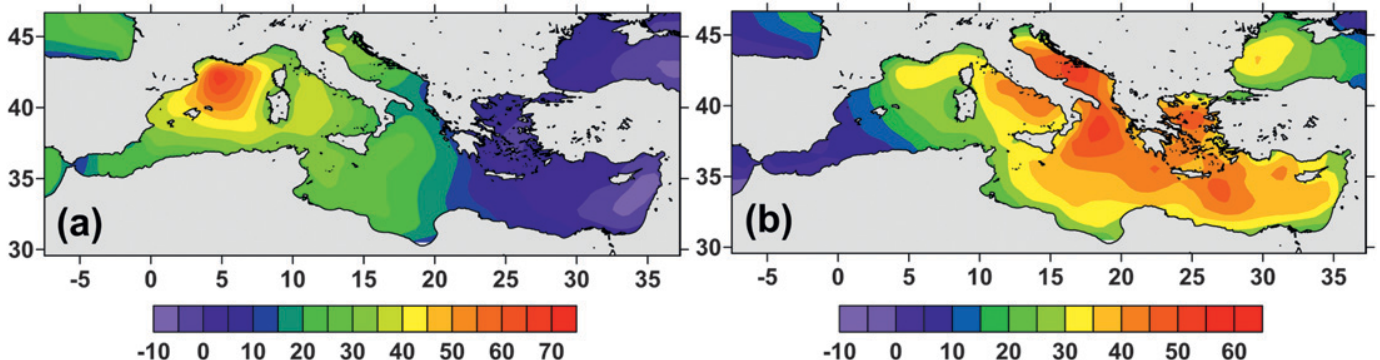

$\begin{array}{lllllllll}-10 & 0 & 10 & 20 & 30 & 40 & 50 & 60 & 70\end{array}$
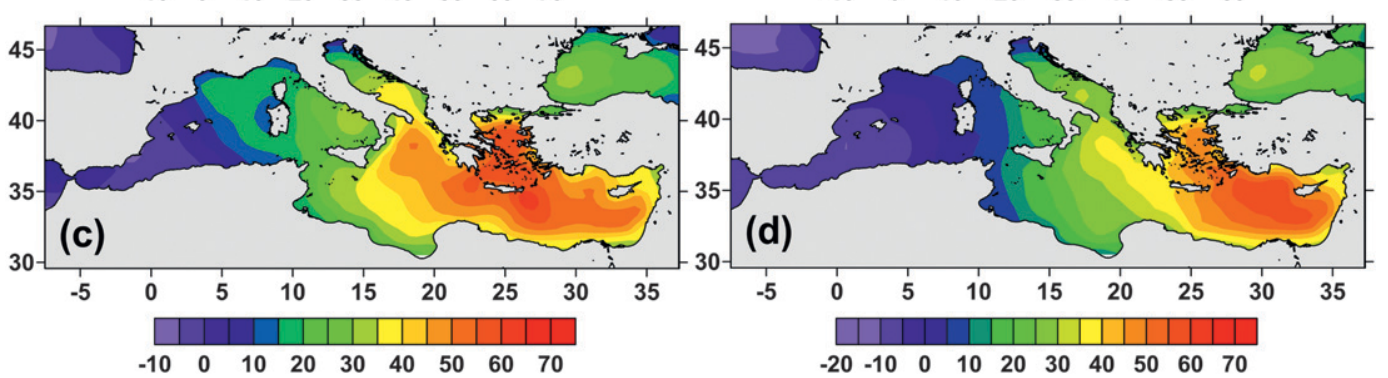

FIG. 8. As in Fig. 2, but for the evaporation anomalies $\left(\mathrm{cm} \mathrm{yr}^{-1}\right)$.

between the MI and Cretan Sea heat flux, indicating that this index is particularly suitable for characterizing the heat loss at this site. The values given in Table 1 are obtained using both deciles. If we segregate out only the lowest decile of $Q_{\text {net }}$, the EA exhibits a stronger impact

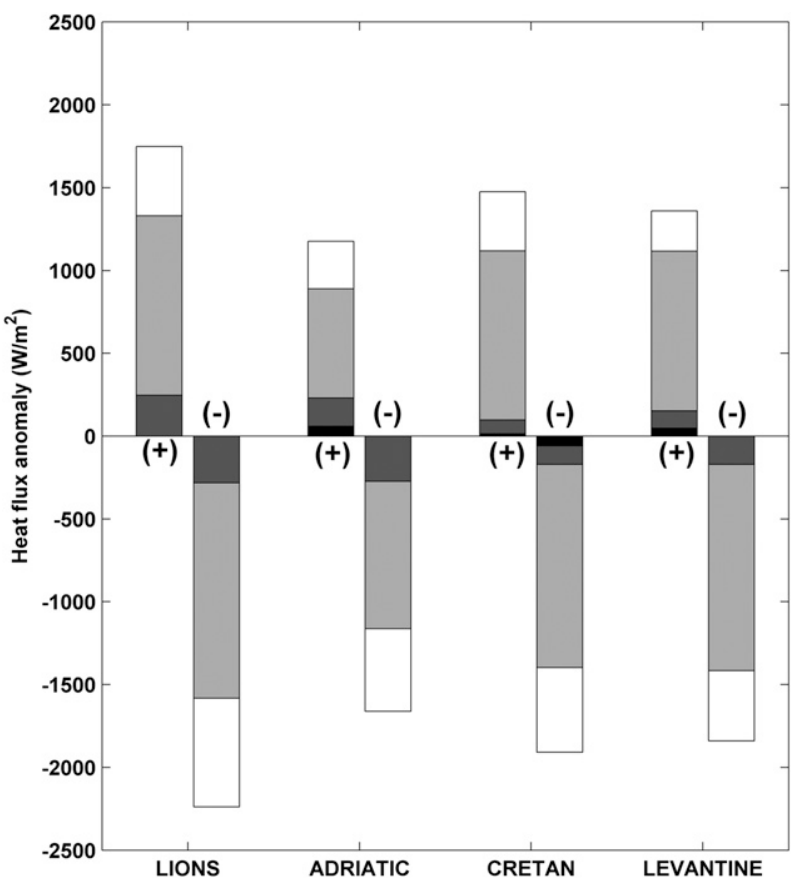

FIG. 9. Contribution of each component to the total amount of the heat flux anomaly corresponding to the uppermost $(+)$ and lowermost $(-)$ deciles during winter months for the period 19582001: shortwave radiation (SW), longwave radiation (LW), latent heat $(\mathrm{LH})$, and sensible heat $(\mathrm{SH})$. on the heat flux minima over the Gulf of Lions $(r=0.92)$ and the Adriatic Sea $(r=0.85)$. Likewise, the MI exhibits a stronger influence on the Cretan Sea $(r=-0.94)$ and the Levantine Sea $(r=-0.88)$. Although the events taken into account are only 25 , the coefficients are much higher than the statistically significance threshold of 0.49 for the $99 \%$ confidence level.

We compare the influence of the four large-scale modes on MI and NCP by compositing the SLP fields that correspond to the difference between the upper and lower deciles of the winter values of these modes (Fig. 10). Correlation coefficients between the MI and NCP, and the large-scale modes are listed in Table 2. The SLP patterns for the four large-scale modes (Figs. 10a-d) are as expected from previous analyses (e.g., Josey et al. 2011, their Fig. 1). The SLP pattern associated with extremes of the MI index (Fig. 10e) does not clearly match on to any of the four large-scale modes suggesting that to some extent it reflects a combination of all four; we now investigate whether this is the case using the correlation statistics.

The MI has been developed to capture SLP variability within the Mediterranean by taking the pressure difference

TABLE 1. Correlation coefficients between the winter (NDJFM) extreme values of $Q_{\text {net }}$ (lowest and highest decile) and the climatic indexes for each location. Bold font signifies the statistically significant coefficients at $95 \%$ confidence level

\begin{tabular}{lrrrrrr}
\hline \hline \multicolumn{1}{c}{ Location } & NAO & EA & EAWR & SCAN & NCP & MI \\
\hline Gulf of Lions & $\mathbf{0 . 4 3}$ & $\mathbf{0 . 8 0}$ & $\mathbf{0 . 4 6}$ & 0.06 & $\mathbf{0 . 4 3}$ & 0.17 \\
Adriatic Sea & 0.26 & $\mathbf{0 . 8 0}$ & $-\mathbf{0 . 3 5}$ & 0.05 & $-\mathbf{0 . 3 7}$ & $-\mathbf{0 . 6 0}$ \\
Cretan Sea & $-\mathbf{0 . 2 9}$ & $\mathbf{0 . 5 0}$ & $-\mathbf{0 . 5 4}$ & 0.27 & $-\mathbf{0 . 5 9}$ & $-\mathbf{0 . 8 5}$ \\
Levantine Sea & 0.04 & $\mathbf{0 . 7 2}$ & $-\mathbf{0 . 4 0}$ & 0.06 & $-\mathbf{0 . 4 9}$ & $-\mathbf{0 . 7 1}$ \\
\hline
\end{tabular}




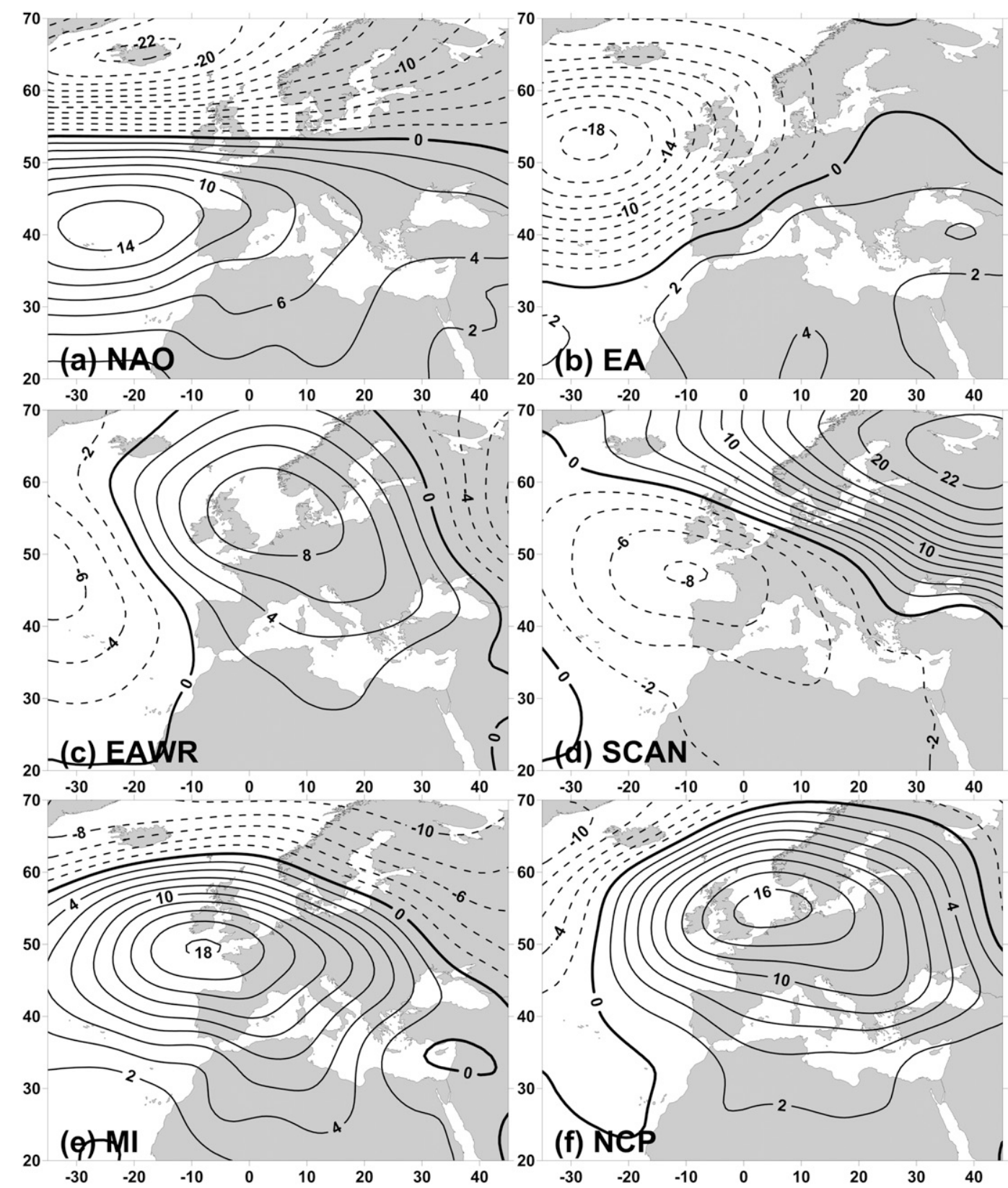

FIG. 10. Composites of the SLP difference field (in hPa) between the upper and lower deciles of the indices values occurring in winter (NDJFM) during the 50-yr period, 1958-2007: (a) NAO, (b) EA, (c) EAWR, (d) SCAN, (e) MI, and (f) NCP.

between the sites in southern France $\left(45^{\circ} \mathrm{N}, 5^{\circ} \mathrm{E}\right)$ and the Levantine Sea $\left(35^{\circ} \mathrm{N}, 30^{\circ} \mathrm{E}\right)$ discussed earlier (section 3$)$. As the four larger-scale modes clearly influence the Mediterranean Sea pressure field we anticipate that the MI will be correlated to some extent with them all. The correlation statistics indicate that this is indeed the case, with the strongest correlation being between the MI and the NAO $(r=0.46)$ and significant relationships also with the $\operatorname{SCAN}(r=-0.32)$ and EAWR $(r=0.33)$. The winter correlation coefficient between the EA and the MI is $r=$ -0.17 indicating a small but marginally significant relationship at the $95 \%$ level. Thus, the MI is significantly correlated to some extent with each of the four modes and should not be considered a separate mode. Instead, it should be treated as an index which captures to a certain extent the influence of each of these modes on the Mediterranean Sea and thus provides a valuable measure of the atmospheric impact on the basin whichever of these 
TABLE 2. Correlation coefficients between the four prominent modes of atmospheric variability in the North Atlantic/Europe region and the MI and NCP during the cold period of the year (NDJFM). Values that are significant at the 95\% level $(r=0.12)$ are highlighted bold.

\begin{tabular}{lccrc}
\hline \hline Index & NAO & EA & SCAN & EAWR \\
\hline MI & $\mathbf{0 . 4 6}$ & $-\mathbf{0 . 1 7}$ & $-\mathbf{0 . 3 2}$ & $\mathbf{0 . 3 3}$ \\
NCP & $\mathbf{0 . 2 1}$ & -0.08 & 0.01 & $\mathbf{0 . 6 4}$ \\
\hline
\end{tabular}

four modes is dominant at a particular time. The utility of the MI has already been demonstrated as our earlier results confirm that it provides the best measure considered here of heat loss in the Cretan Sea and highlights the ability of a simple pressure difference index to capture this process. In contrast to the MI, the NCP is seen to be strongly dependent on the EAWR index $(r=0.64)$, weakly dependent on the NAO $(r=0.21)$, and not significantly correlated with the EA and SCAN patterns. This statistical result is reflected in the strong degree of similarity between the SLP patterns associated with the NCP index (Fig. 10f) and the EAWR mode (Fig. 10c). Thus, the NCP index primarily reflects variations in a single large-scale mode (the EAWR) and does not have the ability of the MI to represent all four of the major atmospheric modes. It is not considered in detail further here.

The above analysis is based entirely on the ARPERA heat flux dataset. The results are very similar when it was repeated using the HIPOCAS dataset (note in this case we have employed one grid point rather than eight for each region). The HIPOCAS SLP composites (not shown) reveal the same characteristics as ARPERA and the contribution of the heat flux components (also not shown) are almost identical to those found previously. Thus, we obtain the same conclusions using two different downscaled reanalyses.

\section{Concluding remarks}

We have considered SLP patterns associated with extreme heat loss that may trigger deep- or intermediatewater convection over the main dense water formation areas in the Mediterranean Sea. For our analysis we have primarily employed SLP composites during events of extreme heat loss by the sea. The SLP composites are complementary tools to the direct use of atmospheric mode index composites that we have considered previously (Josey et al. 2011); they provide a detailed SLP field associated with heat flux extrema. A relatively simple SLP pattern dominated by an anticyclone over northwest Europe with a weaker cyclone to the southeast is found to be associated with strong heat loss in the selected sites with minor variations in pattern structure depending on the site. The key factor generating extreme heat loss is the SLP gradient and the resulting airflow over the studied regions. This is determined by several parameters influenced by the wind speed and direction. The anomalies of $T_{\text {air }}-T_{\text {sea }}$, specific humidity, and evaporation demonstrate that dry, cold winds flowing over the sea enhance the evaporation and the heat loss by means of the turbulent components of the air-sea heat flux. The SLP composites and the additional studied parameters suggest that events of surface cooling over the Cretan Sea and the Levantine Seas can occur under the same largescale atmospheric circulation. The radiative terms display a negligible contribution to the energy anomaly required for the extremes.

Several studies have now shown a relation between the general atmospheric circulation and Mediterranean Sea air-sea heat flux variability (Josey 2003; Josey et al. 2011; Papadopoulos et al. 2012a). Atmospheric patterns associated with events of convection over the Mediterranean are characterized by higher-than-normal pressure over the northeastern Atlantic or northwestern Europe. They result in the transfer of cold air over either the full Mediterranean Sea basin or the eastern subbasin via the EA or EAWR modes of variability (Josey et al. 2011). Our results provide further evidence for the impact of both the EA and EAWR patterns on heat loss at all four of the dense water formation sites considered: the Gulf of Lions, the Adriatic Sea, the Cretan Sea, and the Levantine Sea.

In addition, the MI index, defined as the intrabasin pressure difference between sites in southern France and the Levantine Sea displays a strong influence on the cooling events over the Cretan and Levantine Seas. The MI provides the best measure of heat loss in the Cretan Sea and highlights the ability of a simple pressure difference index to capture this process. However, the MI is not an independent mode and it should be considered as an index that captures the combined influence of the primary CPC modes on the Mediterranean Sea.

Deep- and intermediate-water formation is a complicated process depending on a combination of atmospheric and hydrographic factors. In this study we present the atmospheric conditions that potentially trigger the dense water formation via their impact on ocean heat, and thus buoyancy, loss. However, the atmospheric factor may be inadequate in many cases. For example, strong surface cooling events coming in late autumn-early winter usually do not lead to deep convection as the surface water maintains a large amount of the summer heat content. In other cases, severe surface cooling fails to lead to buoyancy loss when the freshwater input counterbalances the cooling effects. On the other hand, persistent moderate heat loss may lead to deep convection. The study of all the prerequisites that can lead to dense water formation demands a synthetic approach including the 
use of models [e.g., Beuvier et al. (2010) for the eastern basin and Herrmann et al. (2010) for the western basin] and these reveal that the atmospheric component is a fundamental factor. Our analysis has shed further light on the atmospheric processes involved.

Acknowledgments. This study was funded by the European Community's Seventh Framework Programme (FP7/2007-2013) under Grant 287600 with the Policyoriented marine Environmental Research for the Southern European Seas (PERSEUS) project. Michel Déqué is acknowledged for running the ARPEGE-Climate model in its ARPERA configuration. The HIPOCAS dataset has been provided by Puertos de Estado (Spain). We thank the two anonymous reviewers for their constructive comments, which helped to improve this manuscript.

\section{REFERENCES}

Alexander, M. A., and J. D. Scott, 1997: Surface flux variability over the North Pacific and North Atlantic Oceans. J. Climate, 10, 2963-2978.

Artegiani, A., D. Bregant, E. Paschini, N. Pinardi, F. Raicich, and A. Russo, 1997: The Adriatic Sea general circulation. Part I: Air-sea interactions and water mass structure. J. Phys. Oceanogr., 27, 1492-1514.

Barnston, A. G., and R. E. Livezey, 1987: Classification, seasonality, and persistence of low-frequency atmospheric circulation patterns. Mon. Wea. Rev., 115, 1083-1126.

Beuvier, J., and Coauthors, 2010: Modeling the Mediterranean Sea interannual variability during 1961-2000: Focus on the Eastern Mediterranean Transient (EMT). J. Geophys. Res., 115, C08017, doi:10.1029/2009JC005950.

Bond, N. A., and M. F. Cronin, 2008: Regional weather patterns during anomalous air-sea fluxes at the Kuroshio Extension Observatory (KEO). J. Climate, 21, 1680-1697.

Cayan, D. R., 1992: Latent and sensible heat flux anomalies over the Northern Oceans: The connection to monthly atmospheric circulation. J. Climate, 5, 354-369.

Estournel, C., X. Durrieu de Madron, P. Marsaleix, F. Auclair, C. Julliand, and R. Vehil, 2003: Observations and modeling of the winter coastal oceanic circulation in the Gulf of Lyon under wind conditions influenced by the continental orography (FETCH experiment). J. Geophys. Res., 108, 8059, doi:10.1029/ 2001JC000825.

Gündüz, M., and E. Özsoy, 2005: Effects of the North Sea Caspian pattern on surface fluxes of Euro-Asian-Mediterranean seas. Geophys. Res. Lett., 32, L21701, doi:10.1029/2005GL024315.

Herrmann, M., and S. Somot, 2008: Relevance of ERA40 dynamical downscaling for modeling deep convection in the Northwestern Mediterranean Sea. Geophys. Res. Lett., 35, L04607, doi:10.1029/2007GL032442.

—, F. Sevault, J. Beuvier, and S. Somot, 2010: What induced the exceptional 2005 convection event in the northwestern Mediterranean basin? Answers from a modeling study. J. Geophys. Res., 115, C12051, doi:10.1029/2010JC006162.

Hurrell, J. W., 1995: Decadal trends in the North Atlantic oscillation: Regional temperatures and precipitation. Science, 269, 676-679.
Josey, S. A., 2003: Changes in the heat and freshwater forcing of the eastern Mediterranean and their influence on deep water formation. J. Geophys. Res., 108, 3237, doi:10.1029/2003JC001778.

_ S. Somot, and M. Tsimplis, 2011: Impacts of atmospheric modes of variability on Mediterranean Sea surface heat exchange. J. Geophys. Res., 116, C02032, doi:10.1029/2010JC006685.

Kalnay, E., and Coauthors, 1996: The NCEP/NCAR 40-Year Reanalysis Project. Bull. Amer. Meteor. Soc., 77, 437-471.

Konda, M., H. Ichikawa, H. Tomita, and M. F. Cronin, 2010: Surface heat flux variations across the Kuroshio Extension as observed by surface flux buoys. J. Climate, 23, 5206-5221.

Krichak, S. O., P. Kishcha, and P. Alpert, 2002: Decadal trends of main Eurasian oscillations and the Eastern Mediterranean precipitation. Theor. Appl. Climatol., 72, 209-220.

Kutiel, H., and Y. Benaroch, 2002: North Sea-Caspian Pattern (NCP) - An upper level atmospheric teleconnection affecting the Eastern Mediterranean: Identification and definition. Theor. Appl. Climatol., 71, 17-28.

Marshall, J., and F. Schott, 1999: Open ocean convection: Observations, theory, and models. Rev. Geophys., 37, 1-64.

MEDOC Group, 1970: Observation of formation of deep water in the Mediterranean Sea. Nature, 227, 1037-1040.

Özsoy, E., and Coauthors, 1993: A synthesis of the Levantine Basin circulation and hydrography 1985-1990. Deep-Sea Res., 40 (2), 1075-1119.

Papadopoulos, V. P., A. Bartzokas, T. Chronis, D. Georgopoulos, and G. Ferentinos, 2012a: Factors regulating the air-sea heat fluxes in the Aegean Sea. J. Climate, 25, 491-508.

- , H. Kontoyiannis, S. Ruiz, and N. Zarokanellos, 2012b: Influence of atmospheric circulation on turbulent air-sea heat fluxes over the Mediterranean Sea during winter. J. Geophys. Res., 117, C03044, doi:10.1029/2011JC007455.

Ratsimandresy, A. W., M. G. Sotilo, J. C. Carretero, E. Alvarez, and H. Hajji, 2008: A 44-year high-resolution ocean and atmospheric hindcast for the Mediterraneaan Basin developed within the HIPOCAS Project. Coast. Eng., 55, 827-842.

Roether, W., B. B. Manca, B. Klein, D. Bregant, D. Georgopoulos, V. Beitzel, V. Kovacevic, and A. Luchetta, 1996: Recent changes in eastern Mediterranean deep waters. Science, 271, 333-335.

_ B. Klein, B. B. Manca, A. Theocharis, and S. Kioroglou, 2007: Transient eastern Mediterranean deep waters in response to the massive dense-water output of the Aegean Sea in the 1990s. Prog. Oceanogr., 74, 540-571.

Rogers, J. C., 1990: Patterns of low-frequency monthly sea level pressure variability (1899-1986) and associated wave cyclone frequencies. J. Climate, 3, 1364-1379.

Romanou, A., G. Tselioudis, C. S. Zerefos, C. A. Clayson, J. A. Curry, and A. Andersson, 2010: Evaporation-precipitation variability over the Mediterranean and the Black Seas from satellite and reanalysis estimates. J. Climate, 23, 5268-5287.

Samuel, S. L., K. Haines, S. A. Josey, and P. G. Myers, 1999: Response of the Mediterranean Sea thermohaline circulation to observed changes in the winter wind stress field in the period 1980-93. J. Geophys. Res., 104 (C3), 7771-7784.

Schröeder, K., S. A. Josey, M. Herrmann, L. Grignon, G. P. Gasparini, and H. L. Bryden, 2010: Abrupt warming and salting of the Western Mediterranean Deep Water after 2005: Atmospheric forcings and lateral advection. J. Geophys. Res., 115, C08029, doi:10.1029/2009JC005749.

Sotillo, M. G., A. W. Ratsimandresy, J. C. Carretero, A. Bentamy, F. Valero, and F. Gonzalez-Rouco, 2005: A high-resolution 44-year atmospheric hindcast for the Mediterranean Basin: 
Contribution to the regional improvement of global reanalysis. Climate Dyn., 25, 219-236.

Theocharis, A., K. Nittis, H. Kontoyiannis, E. Papageorgiou, and E. Balopoulos, 1999: Climatic changes in the Aegean Sea influence the Eastern Mediterranean thermohaline circulation (1986-1997). Geophys. Res. Lett., 26, 1617-1620.

Wallace, J. M., and D. S. Gutzler, 1981: Teleconnections in the geopotential height field during the Northern Hemisphere winter. Mon. Wea. Rev., 109, 784-812.
Wu, P., and K. Haines, 1996: Modeling the dispersal of Levantine Intermediate Water and its role in Mediterranean deep water formation. J. Geophys. Res., 101 (C3), 6591-6607.

,-- , and N. Pinardi, 2000: Toward an understanding of deepwater renewal in the Eastern Mediterranean. J. Phys. Oceanogr., 30, 443-458.

Yu, L., and R. A. Weller, 2007: Objectively analyzed air-sea heat fluxes for the global ice-free oceans (1981-2005). Bull. Amer. Meteor. Soc., 88, 527-539. 